\title{
HUBUNGAN TINGKAT KESEMBUHAN TUBERKULOSIS PARU DEWASA DENGAN PENGOBATAN METODE DOTS DAN NON DOTS \\ DI RUMAH SAKIT HAJI ABDOEL MADJID BATOE KABUPATEN BATANGHARI PROVINSI JAMBI TAHUN 2011
}

\author{
Putri, G.F.S, ${ }^{1}$ Hisyam, B $^{2}$ \\ ${ }^{1}$ Mahasiswa Fakultas Kedokteran Universitas Islam Indonesia \\ ${ }^{2}$ Departemen Ilmu Penyakit Dalam Fakultas Kedokteran Universitas Islam Indonesia
}

\begin{abstract}
ABSTRAK
Latar Belakang

Tuberkulosis merupakan salah satu masalah kesehatan utama di dunia termasuk di Indonesia. Untuk memberantas TB WHO mencanangkan strategi DOTS sebagai strategi komprehensif untuk mendeteksi dan menyembuhkan TB. Strategi DOTS diharapkan dapat meningkatkan angka kesembuhan TB.
\end{abstract}

\section{Tujuan}

Untuk mengetahui apakah terdapat hubungan antara tingkat kesembuhan pada pasien tuberkulosis paru dewasa dengan pengobatan metode DOTS dan non-DOTS di RS Haji Abdoel Madjid Batoe tahun 2011.

\section{Metode Penelitian}

Penelitian ini merupakan penelitian observasional dengan pendekatan metode crosssectional. Sampel dalam penelitian ini adalah pasien tuberkulosis paru dewasa dengan hasil pemeriksaan BTA (+) yang telah menyelesaikan pengobatan dan dirawat di RS Haji Abdoel Madjid Batoe tahun 2011 dan memenuhi kriteria inklusi dan eksklusi. Analisis data dilakukan dengan uji chi-square.

\section{Hasil}

Dari 184 sampel penelitian, pengobatan dengan metode DOTS sudah dilaksanakan oleh 118 orang, dan 66 orang menggunakan metode non-DOTS. Didapatkan 121 orang sembuh dan 63 orang tidak sembuh. Kesembuhan dengan menggunakan metode DOTS sebesar 90,6\% sedangkan non-DOTS sebesar 24,3\%. Terdapat hubungan antara kesembuhan dan pengobatan metode DOTS ( $\mathrm{p}=0,000$; CI 95\%: 13,105-68,830).

\section{Kesimpulan}

Terdapat hubungan antara tingkat kesembuhan dengan metode pengobatan yang digunakan. Pengobatan dengan metode DOTS menghasilkan kesembuhan lebih tinggi dibandingkan pengobatan metode non-DOTS.

Kata Kunci: Tuberkulosis, Pengobatan TB, Metode DOTS, Kesembuhan 


\section{ABSTRACT}

Background: Tuberculosis was one of main health problems in the world include Indonesia. To eradicated TB, WHO promoted DOTS strategy as a comprehensive strategy to detect and cure TB. DOTS strategy was expected can increase cure rates of TB.

Objective: The aim of this study was to examine whether there were association between cure rates on adult pulmonary tuberculosis with DOTS and Non-DOTS treatments method in Haji Abdoel Madjid Batoe Hospital in 2011.

Methods: This was an observational study with cross-sectional design. The sample of this study was adult pulmonary tuberculosis patient with positive BTA examination who was treated in Haji abdoel Madjid Batoe Hospital in 2011 and had fulfill the inclusion and exclusion criteria. The datas were analyzed using chi-square test.

Results: One hundred and eighty-four subjects were studied. Of these, one hundred eighteen subjects were treated using the DOTS method and sixty subjects were not treated using the DOTS method. The result showed 121 patient were recover and 63 people were not recover. Cure rates with DOTS method were 90,6\% and non-DOTS method were 24,3\%. There were association between cure rates and tuberculosis treatment with DOTS method ( $p=0,000$; CI 95\%: 13,105-68,830).

Conclusion: There were association between cure rates and treatment method to cure tuberculosis. Tuberculosis treatment with DOTS method produced higher cure rates compared tuberculosis treatment wit non-DOTS method.

Keywords: Tuberculosis, TB treatment, DOTS method, Cure Rates

\section{Keywords. Tuberculosis, TB treatment, DOTS method, Cure Rates}

\section{PENDAHULUAN}

Tuberkulosis merupakan salah satu penyakit tertua di dunia yang hingga kini masih menjadi masalah utama kesehatan masyarakat dan secara global masih menjadi isu kesehatan di seluruh dunia. Penyakit ini adalah penyakit menular langsung yang disebabkan oleh bakteri Mycobacterium Tuberculosis yang biasanya menyerang paruparu, meskipun dalam sepertiga kasus dapat pula menyerang organ tubuh lain seperti tulang, kulit, perut dan lain-lain. Menurut Badan Kesehatan Dunia (World Health
Organization $=\mathrm{WHO})$, diperkirakan sekitar sepertiga penduduk dunia telah terinfeksi oleh Mycobacterium Tuberculosis, dimana 95\% kasus tuberkulosis dan 98\% kematian akibat tuberkulosis terjadi pada negara berkembang. ${ }^{1,2,3}$

Angka kejadian penyakit tuberkulosis yang tinggi ternyata juga diiringi dengan tingginya angka kematian akibat TB. Pada tahun 1995, diperkirakan terjadi 3 juta kematian yang diakibatkan TB diseluruh dunia. Selain itu, TB juga memberikan dampak negatif dari segi ekonomi dan sosial 
pasien. Sekitar $75 \%$ pasien TB adalah kelompok usia yang paling produktif secara ekonomis (15-50 tahun). Diperkirakan seorang pasien TB dewasa akan kehilangan rata-rata waktu kerjanya 3 sampai 4 bulan dan mengakibatkan hilangnya pendapatan rumah tangga sekitar 20-30\%. Sedangkan dampak negatif secara sosial adalah penderita TB dapat dikucilkan oleh masyarakat karena penyakit tersebut. ${ }^{3}$

Di Indonesia Tuberkulosis juga menjadi salah satu masalah kesehatan yang utama. Tuberkulosis di Indonesia menduduki peringkat pertama diantara penyakit menular yang menyebabkan kematian, dan menduduki peringkat ke-3 dalam daftar sepuluh penyakit yang menyebabkan kematian. Berdasarkan laporan WHO pada tahun 2009, Indonesia kini menduduki peringkat ke-5 prevalensi tuberkulosis terbesar di dunia. Prevalensi seluruh kasus tuberkulosis di Indonesia pada tahun 2010 adalah 690.000 atau 289 per 100.000 penduduk, dengan angka insidensi seluruh tipe TB 450.000 kasus, sedangkan angka insidensi kasus TB Paru BTA positif tidak terstedia. $^{4,5}$

$$
\text { Tingginya angka kejadian }
$$

Tuberkulosis di dunia mendorong WHO untuk mencanangkan berbagai upaya pemberantasan penyakit ini. Dimulai dari penemuan efek bakteriostatik pada sulfonamide dan streptomisin. Penggunaan kombinasi asam para amino salisilat dan isoniazid. Pengobatan dengan kombinasi rifampisin dan etambutol selama 6 bulan. Hingga akhirnya pada tahun 1995 WHO menganjurkan strategi DOTS (Directly Observation Treatment Shortcourse) sebagai strategi komprehensif untuk menyembuhkan, maupun mendeteksi penderita tuberkulosis. Indonesia mulai menggunakan strategi DOTS sebagai upaya penanggulangan TB pada tahun 1995. Sejak tahun 2000 strategi DOTS dilaksanakan secara nasional di seluruh fasilitas pelayanan kesehatan terutama Puskesmas.,

Strategi DOTS adalah pengawasan langsung pengobatan jangka pendek yang merupakan pengobatan dengan paduan OAT yang telah ditentukan selama minimal 6 bulan. Strategi ini merupakan strategi komprehensif yang dilakukan di seluruh pelayanan kesehatan primer untuk mendeteksi dan menyembuhkan TB dengan harapan menurunkan insidensi TB di masyarakat. Strategi DOTS memiliki 5 komponen kunci yaitu: 1) Komitmen politis dalam pendanaan, 2) Penemuan kasus melalui pemeriksaan dahak mikroskopis yang terjamin mutunya, 3) Pengobatan yang standar, dengan supervisi dan dukungan bagi pasien, 4) Sistem pengelolaan dan ketersediaan OAT yang efektif, 5) Sistem monitoring pencatatan dan pelaporan yang mampu memberikan penilaian terhadap hasil pengobatan pasien dan kinerja program. ${ }^{3,7}$ 
Adanya pengawasan langsung dalam mengonsumsi obat oleh Pengawas Minum Obat (PMO) merupakan pembeda dan merupakan komponen terpenting dalam metode ini. Adanya pengawasan langsung dalam menelan obat diharapkan dapat meningkatkan angka kesembuhan TB sehingga angka kejadian penyakit TB maupun angka kematiannya mengalami penurunan. ${ }^{8}$

Salah satu rumah sakit yang baru menerapkan strategi DOTS sebagai upaya pengendalian TB adalah Rumah Sakit Haji Abdoel Madjid Batoe (HAMBA) yang berada di Kabupaten Batanghari, Provinsi Jambi yang mulai menerapkan strategi DOTS sejak akhir 2010. Angka kejadian tuberkulosis di Provinsi Jambi pada tahun 2010 adalah sejumlah 3.156, sedangkan angka kejadian kasus baru TB di Kabupaten Batanghari adalah 498 kasus. Berdasarkan data dari Rumah Sakit HAMBA angka kasus baru tuberkulosis pada tahun 2010 didapatkan sebanyak 309 kasus. Dari data tersebut dapat disimpulkan bahwa RS HAMBA menjadi fasilitas kesehatan yang sangat berpengaruh dalam penemuan kasus TB dan perawatan pasien. ${ }^{5}$

Tujuan penelitian ini adalah untuk mengetahui apakah terdapat hubungan antara tingkat kesembuhan pasien tuberkulosis paru dewasa dengan pengobatan strategi DOTS dan tidak DOTS di RSUD Haji Abdoel Madjid Batoe, Batanghari, Jambi.

\section{METODE PENELITIAN}

Penelitian ini merupakan penelitian observasional (non-eksperimental) dengan pendekatan cross sectional. Penelitian ini menggunakan data sekunder berupa data rekam medis RS Haji Abdoel Madjid Batoe Batanghari, Jambi. Populasi terjangkau pada penelitian ini adalah seluruh pasien TB yang dinyatakan dengan hasil pemeriksaan BTA (+) yang dirawat dan telah menyelesaikan pengobatan di Rumah Sakit Haji Abdoel Madjid Batoe pada tahun 2011. Pengambilan sampel dilakukan dengan metode consecutive sampling.

Kriteria inklusi pada penelitian ini adalah: 1) Pasien yang berdasarkan rekam medis terdiagnosis TB paru dengan BTA (+) pada tahun 2011 dan telah selesai menjalankan pengobatan, 2) Pasien usia $>18$ tahun. Sedangkan kriteria eksklusi berupa: 1) memiliki riwayat penyakit jantung, stroke, diabetes melitus, 2) meninggal dunia, 3) pindah pengobatan. Data yang diperoleh akan dianalisis dengan menggunakan metode chi-square (kai-kuadrat) dengan bantuan program komputer SPSS 16.0 for windows.

\section{HASIL}

Dari 184 sampel penelitian akan diketahui distribusi pelaksanaan strategi DOTS dan non-DOTS di RS Haji Abdoel Madjid Batoe, karakteristik subyek penelitian berupa distribusi usia dan jenis kelamin, kesembuhan subyek penelitian, 
serta hubungan antara pengobatan TB paru dengan strategi DOTS dan non DOTS terhadap kesembuhan pasien TB paru dewasa di RS Haji Abdoel Madjid Batoe pada tahun 2011. Dari penelitian ini diketahui bahwa pelaksanaan strategi DOTS di RS HAMBA sebesar $64,1 \%$ atau 118 orang sedangkan yang menggunakan strategi non-DOTS sebesar 36,9\% atau 66 orang.

Distribusi karakteristik subyek penelitian dapat dilihat pada tabel 1 , dimana menunjukkan karakteristik berdasarkan jenis kelamin dan usia. Terdapat 119 orang $(64,7 \%)$ yang berjenis kelamin laki-laki, dimana 77 orang $(65.3 \%)$ menggunakan strategi DOTS dalam pengobatannya, sedangkan yang menggunakan pengobatan strategi non DOTS berjumlah 42 orang (34.7\%). Subyek penelitian yang berjenis kelamin perempuan berjumlah 65 orang $(35,3 \%)$, dengan 41 orang $(63.6 \%)$ menggunakan pengobatan TB paru dengan strategi DOTS dan 24 orang (36.4\%) menggunakan strategi non-DOTS.

Karakteristik berdasarkan usia dibagi menjadi 5 kelompok, yakni Kelompok 1 merupakan kelompok subyek penelitian yang berusia 19-29 tahun, kelompok 2 berusia 3039 tahun, kelompok 3 berusia 40-49 tahun, kelompok 4 berusia 50-60 tahun, dan kelompok 5 merupakan kelompok subyek penelitian yang berusia $>60$ tahun. Distribusi karakteristik subyek penelitian dapat dilihat pada tabel 1.

Kesembuhan subyek penelitian menunjukkan 121 orang sembuh dan 63 orang lainnya tidak sembuh di RS HAMBA pada tahun 2011. Kesembuhan dengan strategi pengobatan DOTS menunjukkan 106 orang $(90,6 \%)$ sembuh sedangkan 12 orang $(9,4 \%)$ pasien tidak sembuh. Subyek penelitian dengan pengobatan non-DOTS didapatkan 15 orang $(24.3 \%)$ sembuh, dan 51 orang $(75.7 \%)$ lainnya tidak sembuh.

Penelitian ini bertujuan untuk mengetahui hubungan antara tingkat kesembuhan dengan strategi pengobatan DOTS dan non-DOTS. Setelah dilakukan uji chi-square dengan bantuan SPSS 16.0 for windows didapatkan $p=0,000$ dan CI $95 \%$ 13.105-68.830, sehingga menunjukkan hasil adanya hubungan. Hasil uji chi-square dapat dilihat pada tabel 2. Selain uji chi-square, dilakukan pula penghitungan Rasio Prevalensi (RP) untuk mengetahui seberapa besar hubungan antara strategi pengobatan TB paru terhadap kesembuhan, dimana didapatkan hasil $\mathrm{RP}=3,956$. Hasil perhitungan RP dapat dilihat pada tabel 3. 
Tabel 1 Distribusi Karakteristik Subyek Penelitian

\begin{tabular}{lcccccc}
\hline \multicolumn{1}{c}{ Karakteristik } & \multicolumn{2}{c}{ DOTS } & \multicolumn{2}{c}{ Non-DOTS } & \multicolumn{3}{c}{ Total } \\
\cline { 2 - 7 } & Jumlah & $\%$ & Jumlah & $\%$ & Jumlah & $\%$ \\
\hline Jenis Kelamin & & & & & & \\
Laki-laki & 77 & 65.3 & 42 & 63.6 & 119 & 64.7 \\
\begin{tabular}{l} 
Perempuan \\
\multicolumn{1}{c}{ Jumlah }
\end{tabular} & 11 & 34.7 & 24 & 36.4 & 65 & 35.3 \\
Umur & & 100 & 66 & 100 & 184 & 100 \\
19-29 tahun & 22 & 18.6 & 11 & 16.7 & 33 & \\
30-39 tahun & 34 & 28.8 & 17 & 25.7 & 51 & 27.7 \\
40-49 tahun & 28 & 23.8 & 19 & 28.8 & 47 & 25.5 \\
50-60 tahun & 22 & 18.6 & 11 & 16.7 & 33 & 17.9 \\
$>60$ tahun & 12 & 10.2 & 8 & 12.1 & 20 & 10.9 \\
\multicolumn{1}{c}{ Jumlah } & 118 & 100 & 66 & 100 & 184 & 100 \\
\hline
\end{tabular}

Tabel 2. Hasil Pengujian Chi-Square

\begin{tabular}{|c|c|c|c|c|c|c|c|}
\hline \multirow{3}{*}{$\begin{array}{c}\text { Strategi } \\
\text { Pengobatan }\end{array}$} & \multicolumn{4}{|c|}{ Kesembuhan } & \multirow{3}{*}{ Jumlah } & \multirow{3}{*}{$\mathrm{P}$} & \multirow{3}{*}{ CI 95\% } \\
\hline & \multicolumn{2}{|c|}{ Sembuh } & \multicolumn{2}{|c|}{ Tidak Sembuh } & & & \\
\hline & $n$ & $\%$ & $\mathrm{~N}$ & $\%$ & & & \\
\hline DOTS & 106 & 87.6 & 12 & 19.1 & 118 & & \\
\hline Non-DOTS & 15 & 12.4 & 51 & 80.9 & 66 & 0.000 & $13.105-68.830$ \\
\hline Jumlah & 121 & 100 & 63 & 100 & 184 & & \\
\hline
\end{tabular}

Tabel 3. Hasil Perhitungan Rasio Prevalensi

\begin{tabular}{ccccccc}
\hline & & \multicolumn{2}{c}{ Kesembuhan } & \multirow{2}{*}{ Jumlah } & \multirow{2}{*}{ RP } \\
\cline { 2 - 4 } & & Sembuh & Tidak Sembuh & & \\
\hline \multirow{2}{*}{ Strategi } & DOTS & 106 & 12 & 118 & \multirow{2}{*}{ Pengobatan } \\
\cline { 2 - 5 } & Non DOTS & 15 & 51 & 66 & \multirow{2}{*}{3,956} \\
\cline { 2 - 5 } & Jumlah & 121 & 66 & 184 & \\
\hline
\end{tabular}

\section{PEMBAHASAN}

Hasil penelitian ini menunjukkan bahwa lebih dari separuh sampel penelitian telah menggunakan strategi DOTS untuk pengobatan TB paru, meskipun masih terdapat sampel penelitian yang menggunakan strategi non-DOTS. Hasil penelitian ini didukung oleh penelitian yang dilakukan oleh Balasubramanian et al., (2000), yang mana hampir seluruh pasien dilaporkan telah menggunakan strategi DOTS meskipun terdapat seperempat pasien yang belum menggunakan strategi DOTS. $^{8} \quad 35,3 \%$. Hal ini serupa dengan hasil penelitian
Tetapi, penelitian yang dilakukan Hifzoni (2011) menunjukkan hal berbeda yakni, didapatkannya 63 orang menggunakan strategi non-DOTS dan hanya 29 orang yang menggunakan strategi DOTS di RSUD Selong. ${ }^{9}$

Hasil penelitian ini menunjukkan bahwa pasien tuberkulosis paru dewasa di RS Haji Abdoel Madjid Batoe tahun 2011 didominasi oleh pasien laki-laki yakni sebanyak 119 orang atau $64.7 \%$ sedangkan, pasien wanita sebanyak 65 orang atau $35,3 \%$. Hal ini serupa dengan hasil penelitian 
yang dilakukan Dewi (2011) di RS Panembahan Senopati Bantul. ${ }^{10}$ Tetapi, hasil penelitian yang dilakukan Ari Diansyah (2005) pada penderita Tuberkulosis dewasa BTA (Basil Tahan Asam) positif di Kota Salatiga tahun 2003 memberikan hasil yang berbeda, dengan didapatkan pasien perempuan lebih banyak daripada penderita Laki-laki. $^{11}$

Dominasi pasien TB laki-laki diduga laki-laki memiliki mobilitas yang lebih tinggi dibandingkan perempuan sehingga kemungkinan untuk terpapar kuman penyebab TB lebih besar. Laki-laki memiliki kebiasaan untuk merokok, minum alkohol, dan keluar malam hari yang dapat menurunkan sistem kekebalan tubuh. Selain itu, perempuan sering mendapatkan hambatan untuk mendapatkan pelayanan kesehatan sehingga penemuan pasien perempuan lebih rendah dibandingkan lakilaki. ${ }^{12}$ Pada perempuan ditemukan diagnosis yang terlambat, sedangkan laki-laki lebih cenderung pergi ke pelayanan kesehatan ketika tahu pengobatan $\mathrm{TB}$ gratis sementara perempuan tidak. ${ }^{13}$

Hasil penelitian menunjukkan bahwa pasien TB paru dewasa paling banyak adalah kelompok usia 30-39 tahun, diikuti kelompok usia 40-49 tahun, kemudian kelompok usia 19-29 tahun dan 50-59 tahun. Pasien TB paru dewasa yang paling sedikit adalah pasien dengan kelompok usia 60 tahun keatas. Penelitian yang dilakukan oleh
Sanjaya (2011) memberikan hasil serupa yakni didapatkan distribusi usia pada pasien tuberkulosis paru yang paling banyak adalah kelompok usia 26-40 tahun sebanyak 40,8\%. Tetapi penelitian yang dilakukan Taufik (1999), menunjukkan hal berbeda yakni didapatkannya hasil penderita tuberkulosis dengan BTA positif di RS Persahabatan umumnya berusia diatas 55 tahun. ${ }^{14}$

Sebagian besar penderita TB paru merupakan kelompok usia produktif (15-54 tahun), hal ini disebabkan kelompok usia ini memiliki mobilitas yang cukup tinggi sehingga kemungkinan terpapar kuman M.Tuberculosis lebih besar. ${ }^{3}$ Apabila penderita tuberkulosis terbanyak adalah usia produktif dan tidak ditangani dengan cepat, dapat berdampak pada stabilitas ekonomi suatu negara dan dapat meningkatkan tingkat penularan tuberkulosis karena mobilitasnya yang tinggi. ${ }^{15}$

Hasil penelitian ini menunjukkan bahwa pengobatan dengan strategi DOTS di RS Haji Abdoel Madjid Batoe memiliki tingkat kesembuhan yang lebih besar dibandingkan pengobatan dengan strategi non-DOTS. Hasil ini didukung oleh hasil penelitian yang dilakukan oleh Girsang (2008) yag meneliti angka kesembuhan TB pada Rumah Sakit yang menerapkan strategi DOTS dibandingkan dengan Rumah Sakit yang belum menerapkan strategi DOTS. ${ }^{16}$ Jasmer et al., (2004), juga mendapatkan hasil serupa pada penelitian yang dilakukan di San 
Fransisco, California. Hasil penelitian tersebut menunjukkan tingkat kesembuhan pada pasien yang mendapatkan pengobatan dengan strategi DOTS lebih tinggi dibandingkan pasien dengan pengobatan tanpa pengawasan langsung. ${ }^{17}$

Elemen yang sangat menentukan dalam pengobatan strategi DOTS adalah adanya PMO (Pengawas Menelan Obat). Peran PMO dapat memberikan dukungan positif, keyakinan kepada penderita dan mengingatkan untuk menelan obat, serta memberikan dukungan emosional agar sembuh. Keberadaan PMO akan memastikan penderita menelan obat dan diharapkan sembuh pada akhir pengobatan. Dengan demikian PMO akan lebih menjamin kepatuhan penderita TB untuk menjalani pengobatan secara teratur sampai akhir pengobatan sehingga, kemungkinan untuk sembuh pada akhir pengobatan lebih besar. $^{18,7}$

Analisis chi-square dilakukan untuk mencari hubungan kesembuhan pasien TB paru dengan pengobatan metode DOTS dan non DOTS. Analisis tersebut memberikan hasil $\mathrm{p}=0,000$ yang mana $\mathrm{p}<0,05$. Menurut Sastroasmoro (2009), hasil penelitian dianggap bermakna jika $\mathrm{p}<0,05$. Dengan demikian dapat disimpulkan bahwa terdapat hubungan antara kesembuhan dengan strategi pengobatan, yakni dengan pengobatan strategi DOTS.
Penelitian ini juga menghitung nilai Rasio Prevalensi (RP) dengan hasil perhitungan 3,956. Hasil ini menunjukkan RP >1 yang berarti pengobatan strategi DOTS merupakan faktor yang dapat menyebabkan kesembuhan tuberkulosis paru dewasa.

Selain itu penelitian ini juga mencari interval kepercayaan $95 \%$ (IK 95\%). Nilai IK 95\% mengandung arti diharapkan hasil penelitian yang dilakukan dapat mewakili sebesar $95 \%$ populasi. Setelah melakukan uji analisis nilai IK yang diperoleh mencakup rentang 13.105 - 68.830, dimana rentang tersebut tidak melewati angka 1 sehingga dianggap terdapat hubungan. Namun semakin besar atau lebar rentang nilai IK, maka penelitian semakin tidak mewakili populasi. Sehingga dapat diinterpretasikan bahwa hasil penelitian menunjukkan adanya hubungan antara kesembuhan dengan strategi pengobatan pada sampel namun, tidak dapat mewakili populasi.

Penelitian ini memiliki beberapa keterbatasan, yakni: 1)Keterbatasan validitas dan realibilitas data yang diperoleh, 2)Data rekam medis yang ada di Rumah Sakit masih kurang lengkap, sehingga mempengaruhi data variabel penelitian, 3)Penelitian ini masih terbatas pada strategi pengobatan tanpa melihat faktotr lain yang dapat mempengaruhi kesembuhan TB paru seperti status gizi, atau kebiasaan merokok. 


\section{KESIMPULAN}

Dari penelitian yang telah dilakukan dapat ditarik kesimpulan yakni adanya hubungan antara tingkat kesembuhan tuberkulosis paru dewasa dengan strategi pengobatan yang digunakan, dimana pengobatan strategi DOTS menghasilkan kesembuhan yang lebih besar dibandingkan pengobatan metode non-DOTS di Rumah Sakit Haji Abdoel Madjid Batoe tahun 2011.

\section{DAFTAR PUSTAKA}

1. Masniari, Linda, Tjandra Y. Aditama, Wiwin H. Wiyono, Hudoyo Hupudio. 2005. Penilaian Hasil Pengobatan TB Paru dan Faktor-Faktor yang Mempengaruhinya serta Alasan Putus Berobat di RS Persahabatan Jakarta. Jurnal Respirologi Indonesia, 25:1, 922.

2. Longo, Dan L., Anthony S. Fauci, Dennis L. Kasper, Stephen L. Hauser, J. Larry Jameson, dan Joseph Loscalzo, 2012. Harrison's Principle of Internal Medicine (volume 1, edisi kedelapan belas). The McGraw-Hill Companies: New York.

3. Kementrian Kesehatan Republik Indonesia. 2011. Laporan Situasi Terkini Perkembangan Tuberkulosis di Indonesia Januari-Juni 2011: Jakarta.

4. World Health Organization (WHO). 2010. Global Tuberculosis Control: WHO Report 2010. WHO: Geneva.

5. Kementrian Kesehatan Republik Indonesia. 2011. Pedoman Nasional Penanggulangan Tuberkulosis Indonesia: Jakarta.

6. Girsang, Merryani. 2002. Pengobatan Standar Penderita TBC, Cermin Dunia Kedokteran, 137: 7-9.

7. Tabrani, Zubaedah. 2003. Directly Observed Treatment Shortcourse (Editorial). Jurnal Respirologi Indonesia, 23: 2, 64-66.

8. Balasubramanian, V.N., Oomen K., dan R. Samuel. 2002. DOT or Not? Direct Observation of Anti Tuberculosis Treatment and Patient Outcomes, Kerale States, India, International Journal Tuberculosis and Lung Diseases, 4: 5, 409-413.
9. Hifzoni, Fitria. 2011, Hubungan Pengobatan TB berdasarkan Strategi DOTS (Directly Obseerved Treatment Shortcourse) dan Non DOTS pada Pasien TB Paru Dewasa terhadap Kesembuhan di RSUD Selong Tahun 2009. Skripsi, Jurusan Pendidikan Dokter Fakultas Kedokteran, Universitas Islam Indonesia.

10. Dewi, Retna M., 2011, Perbandingan Implementasi Pengobatan Tuberkulosis Paru Dewasa antara Strategi DOTS dan Non DOTS di RSUD Panembahan Senopati Bantul Tahun 2010, Skripsi, Jurusan Pendidikan Dokter Fakultas Kedokteran, Universitas Islam Indonesia.

11. Diansyah, Ari., 2005. Insidensi dan Tingkat Kesembuhan Penderita Tuberkulosis Dewasa BTA (Basil Tahan Asam) Positif di Kota Salatiga Tahun 2003. Skripsi, Jurusan Pendidikan Dokter Fakultas Kedokteran, Universitas Islam Indonesia.

12. Hudelson, P., 1996. Gender Differentials in Tuberculosis: The Role of Socio-Economic and Cultural Factors. International Journal Tuberculosis and Lung Diseases. 77: 391-400.

13. Nakagawa, M.Y., Ozasa K.,Yamada N., Shimouchi A., Ishikawa, Bam DS. 2001. Gender Difference in Delays to Diagnosis and Health Care Seeking Behavior in A Rural Area of Nepal. International Journal Tuberculosis and Lung Diseases. 5:24-31.

14. Sanjaya, Merysa Setyowati. 2011. Profil Pasien Tuberkulosis Paru yang Mengikuti Program Directly Observed Treatment ShortCourse di Rumah Sakit Imannuel Bandung selama Bulan Mei 2011. Tesis. Universitas Kristen Maranatha.

15. Sihombing, Hendra., Hilaluddin, Sembiring., Zainuddin ,Amir., Bintang Y.M. Sinaga., 2012. Pola Resistensi Primer pada Penderita TB Paru Kategori 1 di RSUP H. Adam Malik, Medan. Jurnal Respirologi Indonesia. 32: 138-45.

16. Girsang Merryani. 2008. Kesembuhan Penderita TB (Tuberculosis) setelah Enam Bulan Pengobatan dengan Strategi DOTS (Directly Observed Treatment shortcourse). Tesis. Universitas Gadjah mada.

17. Jasmer, Robert M., Christopher B. Seaman, Leah C. Gonzalez, L. Masae Kawamura, Dennis H. Osmond, Charles L. Daley., 2004. Tuberculosis Treatment Outcome Directly Observed Therapy Compared SelfAdministered Therapy. American Journal of Respiratory and Critical Care Medicine, 170: 561-566. 
18. Masniari, Linda., Priyanti Z.S., TjandraYoga Aditama., 2007. Faktor-Faktor yang Mempengaruhi Kesembuhan TB Paru. Jurnal Respirologi Indonesia. 27:3, 176-185. 